\title{
Psychosocial Factors and Worker Involvement
}

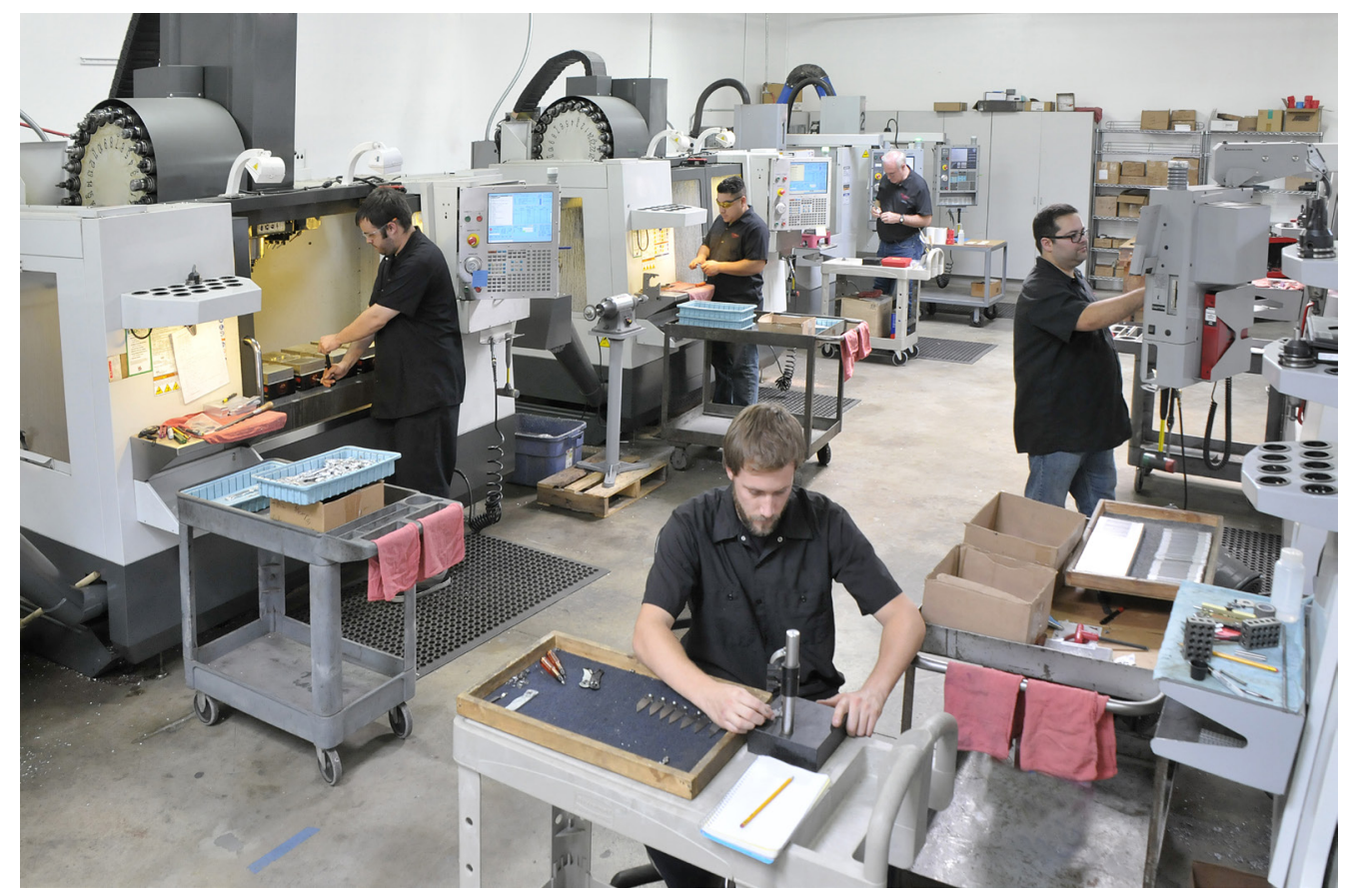

Image reproduced with permission from: Chuck Rausin/Shutterstock.com. All rights reserved.

\section{THIS CHAPTER PROVIDES:}

- Specific psychosocial factors that influence the human's ability to perform and develop.

- Positive and negative effects of stress, task demands and control over the work.

- Different arguments for using models of a workplace to involve users and other stakeholders in participative ergonomics design.

- Characteristics of a psychosocially healthy workplace.

How to cite this book chapter:

Berlin, C and Adams C 2017 Production Ergonomics: Designing Work Systems to Support Optimal Human

Performance. Pp. 107-124. London: Ubiquity Press. DOI: https://doi.org/10.5334/bbe.f. License: CC-BY 4.0 


\section{WHY DO I NEED TO KNOW THIS AS AN ENGINEER?}

Human beings in a workforce are not just a physical and cognitive work resource; they are also individual personalities whose performance is affected by their psychological wellbeing, motivation and subjective experience as an employee. They are also team members trying to navigate social codes and expectations, and furthermore they are a private person outside of the workplace.

In order for workplace design to create the best possible conditions for human workers to perform well, it is important to understand some human psychological reactions, stress tolerance levels, motivating mechanisms, support needs and the need to have influence on how they work. We collect all these aspects under the umbrella term "psychosocial factors". While there are still workplaces today that assume that the human workforce is there to obey instructions blindly, a socially sustainable workplace cannot ignore the importance of interplay between humans, and allowing them opportunities to engage themselves and affect the work that they do. The branch of ergonomics known as macroergonomics concerns itself with the influence of organizations on ergonomics and the interplay between humans, rather than the very specific design of equipment and technology interfaces that characterize human-machine interaction, or microergonomics.

One important aspect of macroergonomics is participative techniques, where different methods are used to involve system users, workers and other stakeholders to engage with their knowledge in making changes to the workplace or giving opinions and ideas in the system design process. Such a workplace has a better chance of attracting and retaining staff for a longer time, at the same time allowing them to become valuable, experienced knowledge resources in the production system.

While it may seem unusual for engineers and workplace designers to care about psychosocial work environment, it is beneficial from a systemic point of view to know how teamwork and human motivation is impacted by the work environment, and how the contents of the previous chapters (physical loading, cognitive ergonomics) are interrelated with effects on the human psyche. In the end, all of these aspects interact to impact the human's ability to perform in the workplace. Focus on this aspect is increasingly understood as part of creating responsibly run workplaces. In 2015, the Swedish Work Environment Authority recently issued a legal provision placing responsibility for organisational and psychosocial work environment on the employer, which means that it is crucial for management roles to grasp what is within their scope of control to ensure psychosocial health. 


\section{WHICH ROLES BENEFIT FROM THIS KNOWLEDGE?}

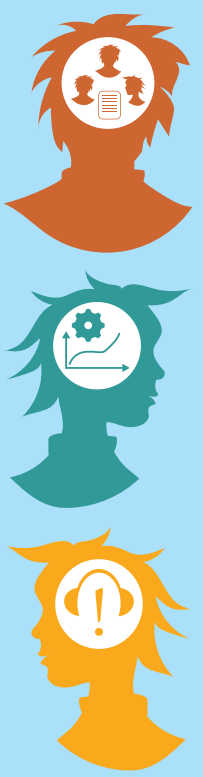

The manager/leader is the primary benefactor of this chapter's knowledge. Knowing which psychosocial stressors and risks are present in work and the workplace is an important precursor to making sustainable long-term decisions about staffing, task allocation, training and competence development, and worker well-being initiatives. The knowledge can be beneficial to building and supporting the growth and performance of teams.

The system performance improver can benefit from an understanding of how the tangible aspects of workplace design are connected to needs and limitations of humans in a social context. The book has so far covered performance aspects on an individual level, but this chapter introduces aspects of teamwork, hierarchy and decision latitude, all of which can be directly supported or hindered by physical and cognitive loading in the workplace.

The work environment/safety specialist benefits from knowing the overall management perspective and the challenges that they face from a personnel-management point of view. Worker safety risks in a psychosocial sense may be difficult to recognize and target without sufficient knowledge of the delayed reactions humans may exhibit to chronic stressors and demotivation; therefore, it is crucial that this work role is able to recognize these risks in their latent state and alert management to the possible consequences.

\subsection{Macroergonomics}

As mentioned before in Chapter 1, the scope of ergonomics has undergone several generations of "widening" its areas of application. The developments in the 1980s directed the field's attentions to the social and organizational context of ergonomics - in a word, macroergonomics. No two organizations are alike, which means that the awareness, support, understanding and emphasis on creating better workplaces varies a lot across company sizes, industrial sectors, history, geographical location, cultures (particularly regarding hierarchy and influence) and the current ideals of the times. Understanding that these social contextual factors can facilitate or hinder positive improvement developments is a central tenet to understanding the meaning and impact of macroergonomics.

Techniques for understanding macroergonomic factors include interview studies, organizational questionnaires, field studies, focus groups, etc. - in other words, there is a lot of emphasis on studying the views and agendas of different human actors, both as individual actors and as teams. Hendrick and Kleiner (2001) describe macroergonomics as being not only top-down (strategic, where leadership states that improvement is a mission), but also "bottom-up" (participatory, where workers get involved) and "middle-out" (focusing on processes). 
In contrast, the type of design challenges this book has covered in previous chapters is sometimes labelled microergonomics; this is when the scope of concern is focused on improving the humanmachine and human-process interface on the basis of human needs and capabilities. However, there is really no other reason to use that label unless it is necessary to make a contextual distinction between that and macroergonomics.

\subsection{Psychosocial environment}

The term psychosocial gained recognition in the late '70s as an important aspect of healthy work environments. It was recognized that human beings are active in, and react to, their immediate surroundings. Insomuch as work processes and work environments affect them, humans also have some level of control and influence over them. This happens on both a psychological level, affecting our thoughts and feelings, but also in a biophysical sense (particularly in the long run) where the psychosocial environment can affect our hormone levels, posture, ability to concentrate, metabolic processes, sleep patterns, etc.

There are many dimensions to the psychosocial environment. First of all, there is the social aspect of working in teams, which may be more or less functional depending on whether the team can accept each other, communicate and collaborate. Surrounding this is the cultural aspect, which dictates the pace of life in that part of the world (in a geographical and time-related sense), and to some degree the order of priorities in life; cultural influence varies depending on where in the world we are, what type of sector we work in, and the changing times. Finally, personal lifestyle as part of the psychosocial environment dictates the individual's balance between work and leisure time, and what is considered a satisfactory quality of life (regarding income, personal involvement at work, opportunities for development and empowerment). This tends to change with the times we live in, but also with different stages of life that the individual goes through.

Certain psychosocial factors can be analysed separately in order to deliberately design the best possible psychosocial conditions in the workplace, as far as this is possible for the employer to control. The aim is to create a workplace that is stimulating, motivating, supportive and sufficiently rewarding for the workforce, hopefully resulting in engagement, creativity, company loyalty and increased competence as a result of employees wanting to stay longer.

\subsection{Positive and negative stress}

Any time that the mind and body are engaged to perform a task to meet time, quality or performance demands, our alertness increases and we are biologically prepared to react (see Chapter 5.4).

Whenever we feel that a situation is stressful, exciting, alarming or the like, regardless of the perceived consequences, it is possible that the body psychosomatically interprets this as danger, releases stress hormones and automatically enters "fight or flight" mode - a condition stemming from humanity's caveman days, where sudden threats of danger required either a fighting response or a quick escape from the danger. What the body does under stress is to release hormones from the adrenal gland, particularly adrenalin and noradrenalin (Kroemer and Grandjean, 1997) and redistribute how the nutrients in the body are used, to prioritize muscular response. The heart rate and breathing rate increase and the senses become more acute, but the body directs resources and nutrients away from processes like digestion, regrowth, learning and the immune system. 
When we are in a challenging situation but confident of being able to complete the task successfully, the adrenaline-kick is only temporary and can be called positive stress, since it serves to increase our alertness and stimulate us with a manageable challenge ${ }^{1}$. Once the task is completed we experience a drop in adrenaline and probably a sense of success that may be chemically reinforced. However, in situations where we feel that we are unable to succeed, and especially if they occur very frequently, the stress becomes negative stress. If we spend large amounts of time in states of negative stress, never letting the adrenal hormone levels fall again, we run the risk of suffering chronic stress symptoms such as ill-health, an overworked heart, anxiety, muscle tension, digestive problems, high blood pressure, exhaustion and weakened capacity to repair and recover. For this reason, it is essential to remember that workplace stressors are not just caused by obvious time restrictions; we may also be stressed by high demands, bad communication, emotional triggers and relational malfunctions like conflicts and interpersonal irritations.

\subsection{Boredom}

Another important aspect of workplace psychosocial health is boredom - the mental state that occurs when the level of stimuli in an environment is perceived as low and monotonous enough for an individual to stop concentrating at the task at hand, usually as a result of a mismatch between the task demands and the competence or skill level of the individual. The negative consequences of boredom include deactivation of higher nervous centres in the brain, feelings of weariness, and lack of alertness that may lead to quality deficiencies or errors.

The most negative state of boredom (from a motivational and alertness point of view) occurs when the task is not monotonous enough for the worker to think about other things entirely if attention is slipping in and out of concentrating on the task because it is not entirely internalized as a routine skill, the worker may feel frustrated. Vigilance, or sustained attention, is a taxing mental state for most humans, especially if stress is part of the work situation. A related, purely emotional tension may occur when the worker feels inner conflict about whether they wish to continue performing the task to the set requirements, or whether they want to be done with it. This emotional tension may over time lead to job dissatisfaction and a deliberate decrease in performance quality.

To counteract boredom, the following points are worth considering in task and workplace design:

- Carefully match the level of the worker's competence with the difficulty of the task.

- Encourage alertness and opportunities for recovery, to make sure workers feel fresh and ready to work - fatigue in itself can exacerbate boredom.

- Avoid work conditions that can increase boredom: solitary work with no contact between colleagues; dim lighting; too-warm climate; very brief and repetitive work cycles; too many noncritical alerts that do not require decisions or action.

- Learners are often more content to do a simple task while they are still in a learning process.

- Design a learning scheme into the tasks, perhaps by "unlocking" increasing levels of difficulty.

(Adapted from Kroemer and Grandjean, 1997 p. 220)

To add some nuance, some recent scientific results from the field of psychology (Gasper and Middlewood, 2014) have re-evaluated boredom, seeing it as a source of creativity and a needed window for daydreaming and reflection in a world that is increasingly distractive and stressful. The study showed 
that test participants who were bored outperformed stressed participants in creative thinking. However, for our purposes of designing a production workplace, we are targeting the kind of distractive boredom that can lead to slips, errors and mistakes.

\subsection{Motivation}

Generally, motivation can be defined as the mental state where a task or overall goal carries meaning for the person performing it, which increases their willingness to take action to complete specific goals.

It is useful to distinguish between the reasons that motivate an individual to act or pursue a goal, or even accept certain conditions. When a task is perceived as meaningful in itself and the individual voluntarily applies effort and time, this is called intrinsic motivation. When the task in itself may not be enough to motivate a person to do something, there may be other reasons - such as a reward, a higher overall goal (of which the task is a step on the way), a sense of developing skill and selfactualization, or getting recognition for the effort or achievement. Such external motivators are called extrinsic, and may cause a person to put up with some discomfort or inconvenience to complete the task, because the end result of completing it brings the person closer to an overall goal. Some of these goals may relate to human needs, which are compelling physiological and psychological drives to survive, thrive and self-actualize.

A classic and well-known model for the hierarchy of human motivational factors is Maslow's (1943) Hierarchy of Human Needs (Figure 6.1), which is most often illustrated as a pyramid, and explained (in Maslow's words) as "When the most prepotent goal is realized, the next higher need emerges" (p.370).

SELF-

ACTUALIZATION

Personal growth, morality,

creativity, fulfillment,

spontaniety, problem-solving

SELF-ESTEEM

Achieving skill and mastery, confidence,

recognition, respect

BELONGING / LOVE

Friends, family, sexual intimacy, community

\section{SAFETY}

Security of body, employment, resources, health; stability, freedom from fear

PHYSIOLOGICAL NEEDS

Food, Shelter, Water, Warmth, Sleep

Figure 6.1: Maslow's hierarchy of human needs (adapted from Maslow, 1943).

Illustration by C. Berlin, based on Maslow (1943). 
Although this model has been debated and updated in various instalments, its historical and cultural impact can be considered immense on the general public's mental model of human needs and drives. It is shown here mostly for cultural reference.

An alternative classification of human needs has been presented by the Chilean researcher and activist Manfred Max-Neef (1992), who defined nine basic human needs and stated that a) they are not hierarchical, b) not substitutable, and c) that they do not vary between cultures. Each human need is equally important for a human being to be healthy. Table 6.1 lists the nine basic needs, which in turn can be fulfilled by satisfiers - these are ways of being, having, doing or interacting that contribute to addressing human needs. According to Max-Neef, a non-fulfilled need of any kind is a form of human poverty.

In a work design context, it is safe to say that certain motivational factors that appeal to the needs concerning our means for survival - in modern industrialized terms, our livelihood. Certain factors must be in place for anyone to even consider taking on a task or job and staying engaged. These basic conditions are known as hygiene factors and include basic remuneration (payment) and guarantees for well-being such as appropriate salary level, work hours, recreation opportunities, development opportunities, social contact, etc. Some of these hygiene factors may vary across cultures, ages, stages in life and levels of skill or education. Sadly, some living conditions in the world are so desperate that in order to make a living, workers will accept high levels of danger to their safety and health in order to make a livelihood - sometimes at the cost of debilitating injuries that may limit their future ability to work and earn a livelihood, or a loss of human rights (such as having travel documents confiscated).

\subsection{Psychosocial factors coupled to tasks}

Although many measurement methods exist to somehow quantify stress levels, motivation, engagement, etc., many of them become an uncertain basis for changes because the reasons for experiencing stress vary from individual to individual and across ages depending on their personal life situation, education level, stage in a learning process, experience with the current tasks at hand, relations with and acceptance from colleagues, etc. It may be a good initiative to monitor the stress levels of a workforce for the purpose of introducing better support through design or planning of human resources, but it is important to remember that these measurements never stay static.

Attempts have been made to capture a holistic measurement of task workload, including both the task-related and the psychosocial aspects. As a refresher, Figure 6.2 reprises the NASA- TLX scale (Hart and Staveland, 1988) designed to measure workload. Many of the things asked for, although they are asked in a way that makes each answer individual and subjective (i.e. the scale is not absolute across humanity), can give work and workplace designers a good idea if the system's overall performance is in danger due to job dissatisfaction.

\subsection{Demand-control-support model}

Karasek (1979) studied the interaction between stress-inducing psychosocial factors and came up with a now classic model explaining how work demands and the level of worker's control over their tasks (decision latitude) influence stress levels at work. The axes of these dimensions simply designate the status of being "high or low", and the resulting four zones explain what stress-level 
Table 6.1: Max-Neef's (1992) nine categories of human needs, and the four categories of satisfiers that can fulfil these needs (taken from Hitchcock and Willard, 2013 p.2).

\begin{tabular}{|c|c|c|c|c|}
\hline Need & Being (qualities) & Having (things) & Doing (actions) & Interacting (settings) \\
\hline Subsistence & $\begin{array}{l}\text { physical and mental } \\
\text { health }\end{array}$ & food, shelter, work & $\begin{array}{l}\text { feed, clothe, rest, } \\
\text { work }\end{array}$ & $\begin{array}{l}\text { living environment, } \\
\text { social setting }\end{array}$ \\
\hline Protection & $\begin{array}{l}\text { care, adaptability, } \\
\text { autonomy }\end{array}$ & $\begin{array}{l}\text { social security, } \\
\text { health systems, work }\end{array}$ & $\begin{array}{l}\text { co-operate, plan, } \\
\text { take care of, help }\end{array}$ & $\begin{array}{l}\text { Social environment, } \\
\text { dwelling }\end{array}$ \\
\hline Affection & $\begin{array}{l}\text { respect, sense of } \\
\text { humour, generosity, } \\
\text { sensuality }\end{array}$ & $\begin{array}{l}\text { friendships, family, } \\
\text { relationships with } \\
\text { nature }\end{array}$ & $\begin{array}{l}\text { share, take care of, } \\
\text { make love, express } \\
\text { emotions }\end{array}$ & $\begin{array}{l}\text { privacy, intimate } \\
\text { spaces of togetherness }\end{array}$ \\
\hline Understanding & $\begin{array}{l}\text { critical capacity, } \\
\text { curiosity, intuition }\end{array}$ & $\begin{array}{l}\text { literature, teachers, } \\
\text { policies, educational }\end{array}$ & $\begin{array}{l}\text { analyze, study, } \\
\text { meditate, } \\
\text { investigate }\end{array}$ & $\begin{array}{l}\text { schools, families, } \\
\text { universities, } \\
\text { communities }\end{array}$ \\
\hline Participation & $\begin{array}{l}\text { receptiveness, } \\
\text { dedication, sense of } \\
\text { humour }\end{array}$ & $\begin{array}{l}\text { responsibilities, } \\
\text { duties, work, rights }\end{array}$ & $\begin{array}{l}\text { cooperate, dissent, } \\
\text { express opinions }\end{array}$ & $\begin{array}{l}\text { associations, } \\
\text { parties, churches, } \\
\text { neighbourhoods }\end{array}$ \\
\hline Leisure & $\begin{array}{l}\text { imagination, } \\
\text { tranquility, sense of } \\
\text { humour, spontaneity }\end{array}$ & $\begin{array}{l}\text { games, parties, peace } \\
\text { of mind }\end{array}$ & $\begin{array}{l}\text { day-dream, } \\
\text { remember, } \\
\text { relax, have fun }\end{array}$ & $\begin{array}{l}\text { intimate spaces, } \\
\text { places to be alone, } \\
\text { landscapes }\end{array}$ \\
\hline Creation & $\begin{array}{l}\text { imagination, } \\
\text { boldness, } \\
\text { inventiveness, } \\
\text { curiosity }\end{array}$ & $\begin{array}{l}\text { abilities, skills, work, } \\
\text { techniques }\end{array}$ & $\begin{array}{l}\text { invent, build, } \\
\text { design, work, } \\
\text { compose, interpret }\end{array}$ & $\begin{array}{l}\text { spaces for expression, } \\
\text { workshops, audiences }\end{array}$ \\
\hline Identity & $\begin{array}{l}\text { sense of belonging, } \\
\text { self-esteem, } \\
\text { consistency }\end{array}$ & $\begin{array}{l}\text { language, religions, } \\
\text { work, customs, } \\
\text { values, norms }\end{array}$ & $\begin{array}{l}\text { get to know } \\
\text { oneself, grow, } \\
\text { commit oneself }\end{array}$ & $\begin{array}{l}\text { places one } \\
\text { belongs to, } \\
\text { everyday } \\
\text { settings }\end{array}$ \\
\hline Freedom & $\begin{array}{l}\text { autonomy, passion, } \\
\text { self-esteem, open- } \\
\text { mindedness }\end{array}$ & equal rights & $\begin{array}{l}\text { dissent, choose, } \\
\text { run risks, develop } \\
\text { awareness }\end{array}$ & anywhere \\
\hline
\end{tabular}

Note that these satisfiers are general, not targeted at production environments, but they are important from a holistic personnel-health point of view.

effects their combination may have on workers. Figure 6.3 shows the four zones of psychosocial health, describing them as "active, low-strain, passive, high-strain" in the order of increasing psychosocial risk.

A later version of this model was developed by Karasek and Theorell (1990) where an additional dimension was mapped: that of social support, a factor that can help stressed workers manage the job strain. Figure 6.4 shows this more nuanced model as a three-dimensional representation. 


\section{NASA Task Load Index}

Hart and Staveland's NASA Task Load Index (TLX) method assesses work load on five 7-point scales. Increments of high, medium and low estimates for each point result in 21 gradations on the scales.

\begin{tabular}{|l|l|l|l|l|l|}
\hline Name & Task & Date \\
\hline Mental Demand \\
\begin{tabular}{|l|l|l|l|l|l|l|l|l|l|l|l|l|l|}
\hline \\
\hline
\end{tabular} \\
Very Low & How mentally demanding was the task?
\end{tabular}

Physical Demand How physically demanding was the task?

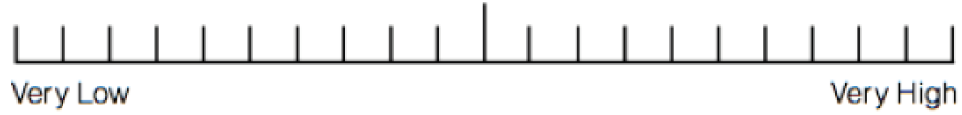

Temporal Demand How hurried or rushed was the pace of the task?

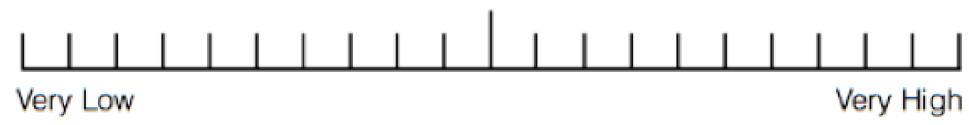

Performance How successful were you in accomplishing what you were asked to do?

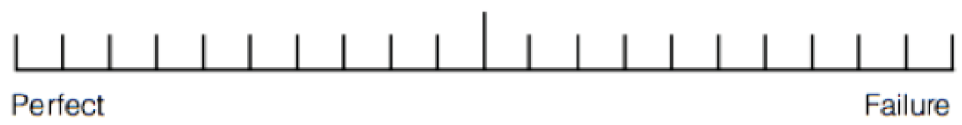

Effort How hard did you have to work to accomplish your level of performance?

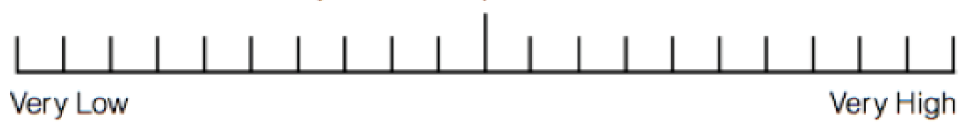

Frustration How insecure, discouraged, irritated, stressed, and annoyed wereyou?

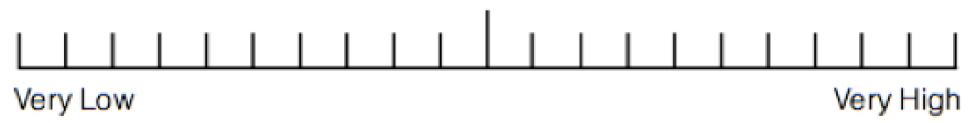

Figure 6.2: The NASA-TLX form with its six sub-scales (NASA, 2014).

Source: NASA Ames Research Center; used with permission. 


\section{Psychological demands}

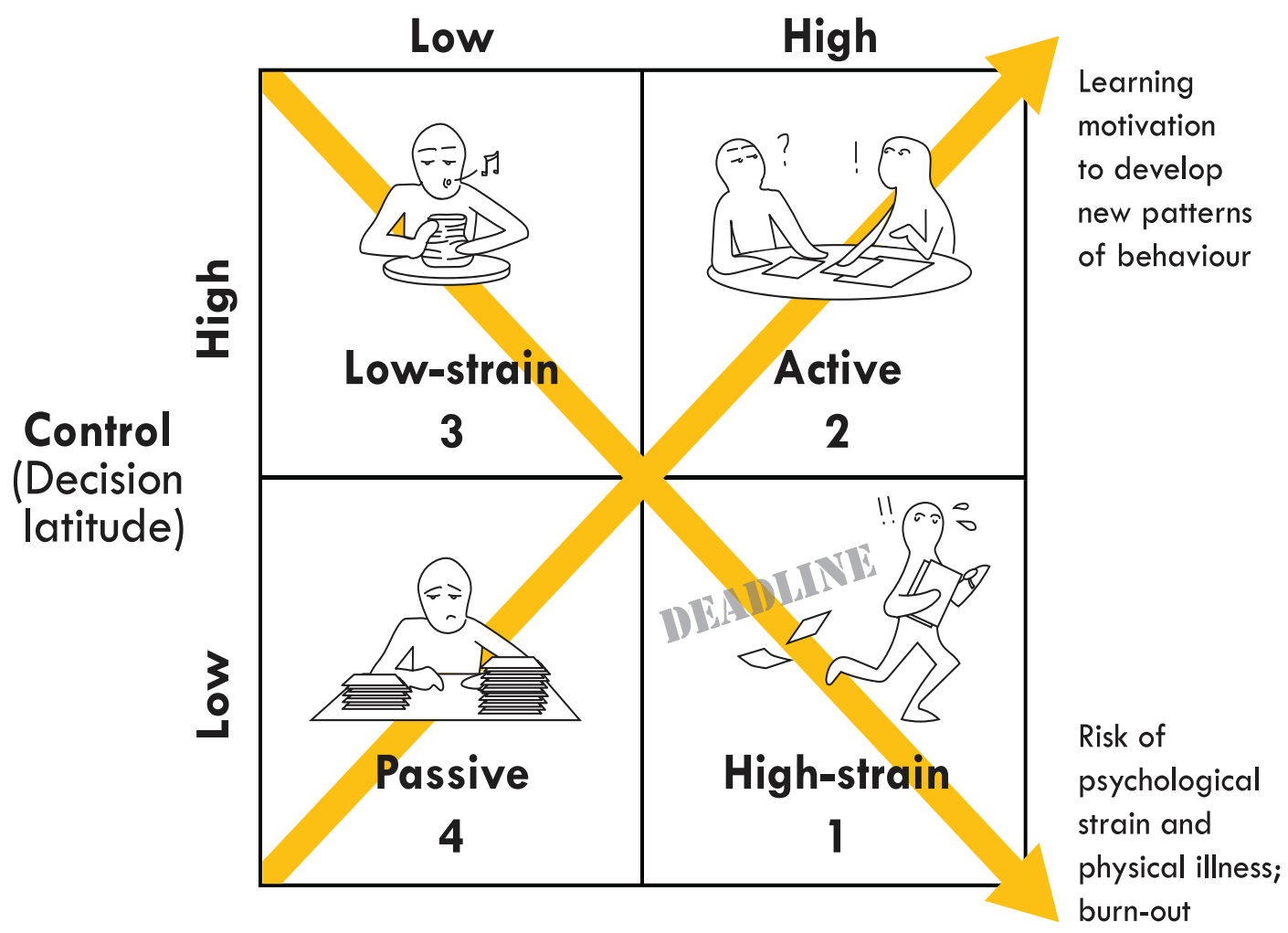

Figure 6.3: The relation between demand and control (decision latitude), adapted from Karasek (1979). Illustration by C. Berlin, based on Karasek (1979).

\subsection{Participatory ergonomics}

One of the most central improvement techniques from the macroergonomic approach is participatory ergonomics (also known as participatory design ${ }^{2}$ ) defined by Wilson as "the involvement of people in planning and controlling a significant amount of their own work activities, with sufficient knowledge and power to influence both processes and outcomes in order to achieve desirable goals" (1995 p. 37).

\subsection{A process for participatory design}

Vink et al. (2005) described the participatory design process as consisting of six steps, as shown in Table 6.2. 


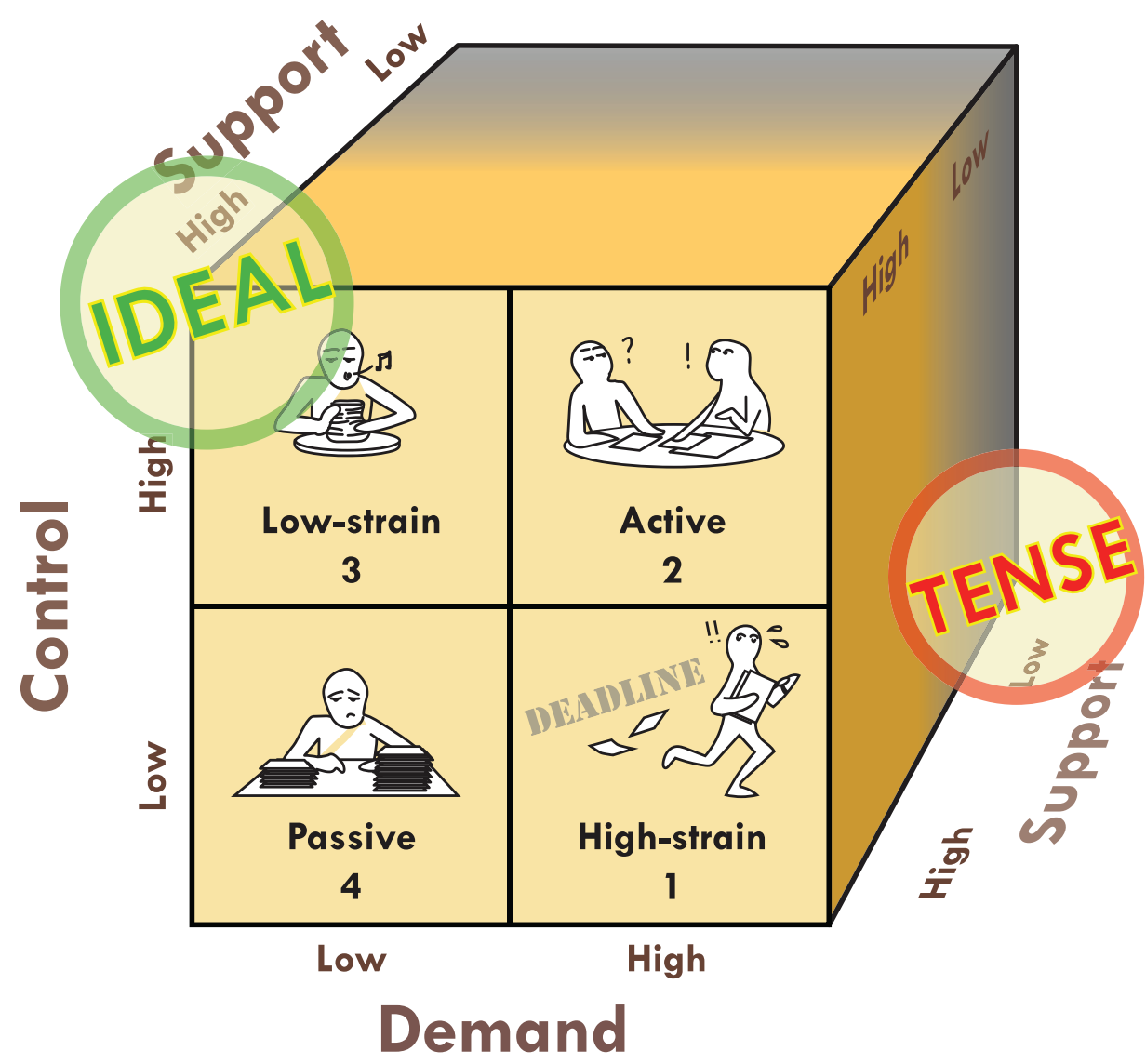

Figure 6.4: The relation between demand, control (decision latitude) and support, as theorized by Karasek and Theorell, 1990.

Illustration by C. Berlin, based on Karasek and Theorell (1990).

\subsection{Using models of the design solution}

One very effective strategy for eliciting discussion and feedback from the participants is to use different types of models representing the work system as a basis for discussion. Having a visible representation of the workplace layout and how the new design solution fits into it helps to direct the attention of the participants towards discussing design rather than general well-being aspects. This can be a great tool for designers to leverage not only good ideas, knowledge and suggestions, but also to encourage acceptance for the final solution among the end-users. Having a visual representation of the workplace offers an opportunity to point to specific details and relate some of the feedback to human movement and the dimensions of the human body. 
Table 6.2: The participatory design process, adapted from Vink et al. (2005) and Kuijt- Evers (2006).

\begin{tabular}{|c|c|}
\hline 1) Preparation & $\begin{array}{l}\text { The stakeholders are informed of the planned change project and its overall goals. } \\
\text { The stakeholders may include end users, management, designers, specialists, } \\
\text { operators, maintenance personnel, etc. The overall strategy for how to involve } \\
\text { them and turn their feedback into a solution is discussed. }\end{array}$ \\
\hline $\begin{array}{l}\text { 2) Analysis of tasks, } \\
\text { work and health }\end{array}$ & $\begin{array}{l}\text { A baseline for the design is established by studying the current practices, } \\
\text { needs, problems and solutions in the context of the workplace. This can be } \\
\text { achieved using observations, interviews (group or individual), simulation or } \\
\text { questionnaires. The purpose here is not to influence, but to study how things } \\
\text { are done. }\end{array}$ \\
\hline $\begin{array}{l}\text { 3) Selection of } \\
\text { improvements and } \\
\text { design }\end{array}$ & $\begin{array}{l}\text { A requirement specification for solving the identified problems and meeting } \\
\text { the identified needs is created. This should build on user requirements and } \\
\text { wishes. This is a good stage to involve the users in a participatory process, } \\
\text { allowing them to engage in a forum where they can suggest ideas and improve- } \\
\text { ments. When this input has been collected, new design ideas can be tested and } \\
\text { made. A good way to make more involvement possible is to build models of the } \\
\text { new design proposals, either in 2D or 3D format, for the participants to relate } \\
\text { to in discussions. }\end{array}$ \\
\hline $\begin{array}{l}\text { 4) Pilot study with the } \\
\text { improvements }\end{array}$ & $\begin{array}{l}\text { This is the stage at which testing occurs on the basis of the design models - they } \\
\text { can be tested in the context of the real, existing workplace, in a "clinical" setting } \\
\text { to direct attention away from details that shouldn't be the subject of feedback, or a } \\
\text { mix between these environments. }\end{array}$ \\
\hline 5) Implementation & $\begin{array}{l}\text { After one or more iterations of steps } 3-4 \text {, the new design can be implemented in } \\
\text { its real context. The participants are informed and educated about the implica- } \\
\text { tions of introducing the new design. }\end{array}$ \\
\hline 6) Evaluation & $\begin{array}{l}\text { After an adjustment period where the end users get accustomed to the new } \\
\text { solution, an evaluation can be carried out to determine if well-being and system } \\
\text { performance have increased compared to the baseline established in step 2. If } \\
\text { found necessary, this participatory evaluation can become the basis for further } \\
\text { improvements. }\end{array}$ \\
\hline
\end{tabular}

One important thing to remember is that the detail level of the model will determine the level of feedback gained from the participants; for example, if you do not want feedback on small details like the exact size and shape of buttons, but rather the heights, depths and layout of work areas and tables, then it is possible to temporarily omit those details in the model, explaining to the participants what type of feedback you are expecting. Another useful technique is to ask the participants to imagine a scenario where they are trying to complete a task in the new design solution. This type of imaginary goal can help the participants direct their feedback towards things the designer cannot know or guess, such as experiences, work procedures, anecdotes, safety concerns and workarounds. Different model representations have different pros and cons, as follows: 


\section{$2 D$ drawings}

Two-dimensional drawings constitute a rather common representation of new workplace designs. Quite frequently they are shown as technical drawings from the top or side view, describing the layout. Although there may be a cultural expectation that these drawings are easy to understand, there is a risk that the bare-bones flat representation on paper or screen does not allow the users to evaluate all aspects of working in the new design solution. Some pros of $2 \mathrm{D}$ drawings include the ease of distributing the information to all different participants, including the ability to mail or send them to faraway participants, and the fact that writing and drawing on these representations allow individuals to comment and suggest changes rather easily. However, it is difficult to get a fair representation of heights, depths, distances and the relation of these dimensions to the human body. Also, a 2D drawing may seem like a finished architectural blueprint that does not encourage workers to suggest further changes.

\section{$3 D$ scale models}

It is possible to build a small-scale three-dimensional representation of the design idea, using cheap materials such as cardboard, clay, foam board and glue, etc. To do this requires materials, work time and some model-building competence, and perhaps also a modelled human representation to go with it, in order for the participants to judge how sizes, depths and distances relate to the human worker's size. Three-dimensional scale models are comparatively cheap, easy to change, can be easily transported and stored, and provide very a good discussion basis for feedback in groups. Also, depending on the chosen detail level and the level of "finish" of the model, participants may feel that they have the possibility to suggest changes by building or modifying the actual model using the same materials as the designer. It is important not to intimidate participants from changing, moving or manipulating the model. At the same time, the disadvantages are that the time and effort necessary to make the model(s) might result in only one or a few being built, and they essentially demand the physical presence of the participants in order for evaluation to take place.

\section{D full-scale models (mock-ups)}

A full-scale model of the new design has the advantage that no human representation is needed; the users themselves can relate their own bodies to the new design proposal, which is particularly useful when judging movement patterns, reach distances, lines of sight and general comfort. The visual and tactile representation of the workplace may further enrich the feedback given from participants, and elicits good feedback in group discussions. Like with 3D scale models, model building competence, materials and time are needed, but it is also possible to suggest that the model is not a finished design, by making the representation seem "rough at the edges" and open to modification.

It is also particularly important in a full-scale model to be deliberate about the level of detail shown to the participants, in order to direct attention and feedback to the design aspects that the designer wants commented. Full scale models also demand the physical presence of the participants in order for evaluations to take place - not to mention considerable space, and the license to occupy that space for some time until the evaluation is over. 


\begin{tabular}{|c|c|c|c|c|c|}
\hline 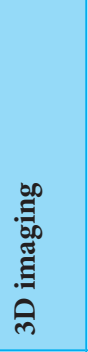 & 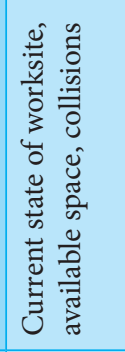 & 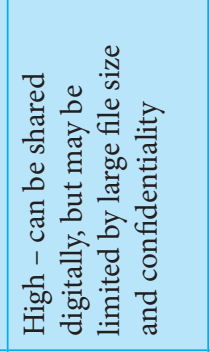 & 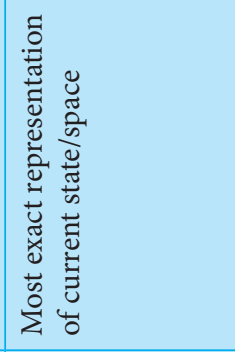 & 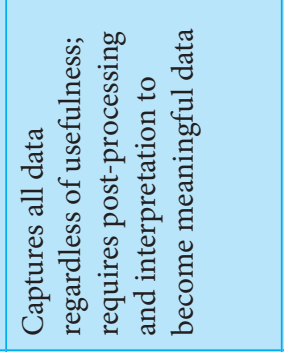 & 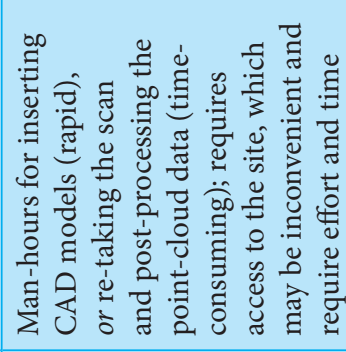 \\
\hline 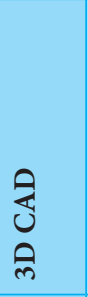 & 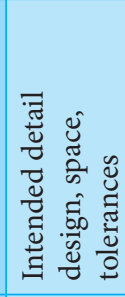 & 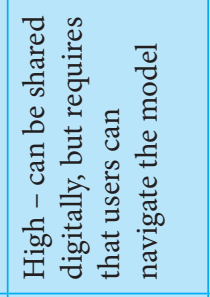 & 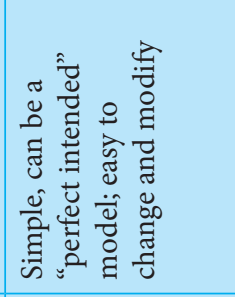 & 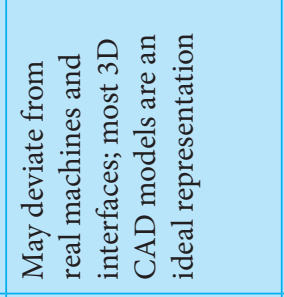 & 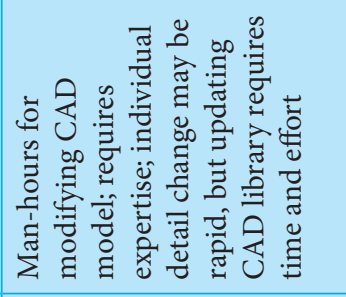 \\
\hline 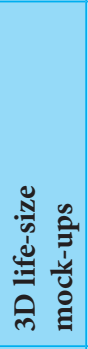 & 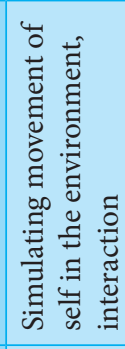 & 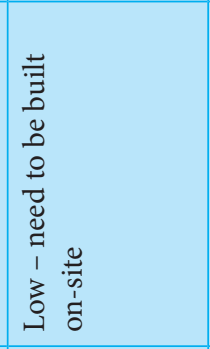 & 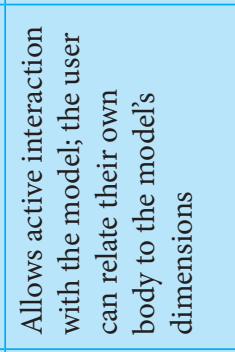 & 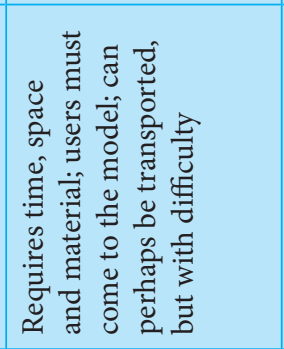 & 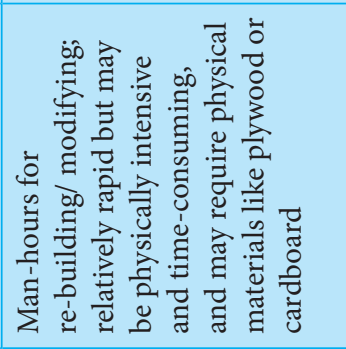 \\
\hline 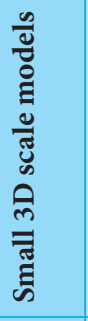 & 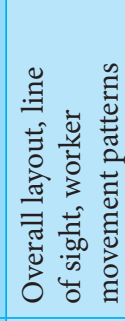 & 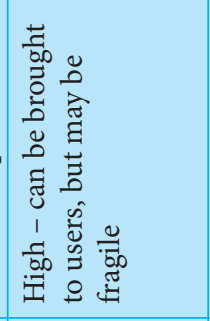 & 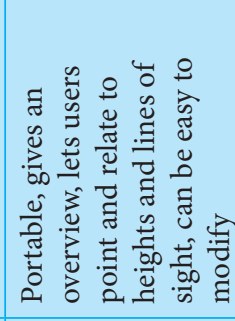 & 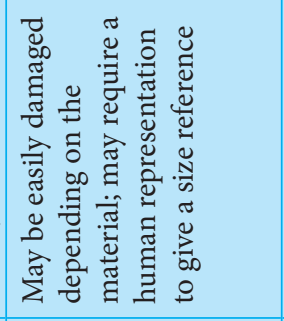 & 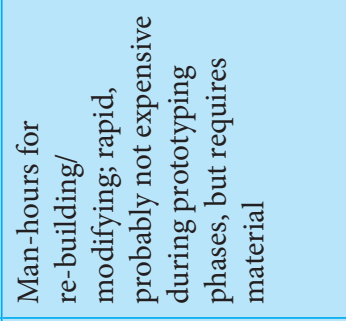 \\
\hline 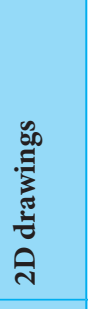 & 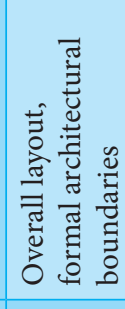 & 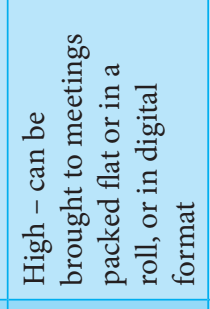 & 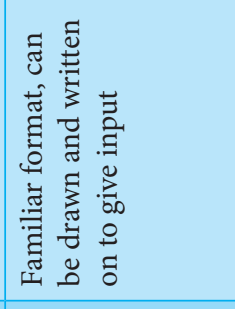 & 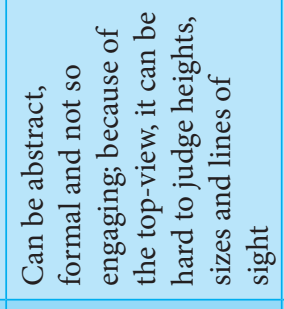 & 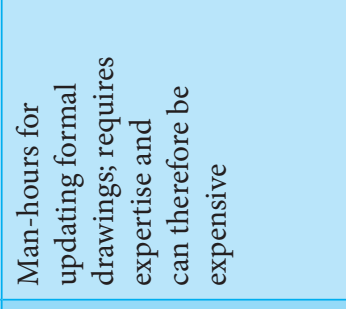 \\
\hline & 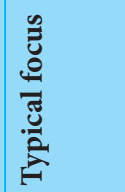 & 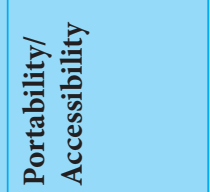 & 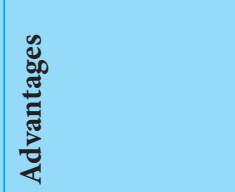 & 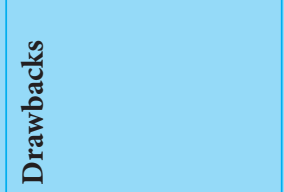 & 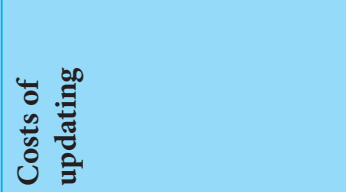 \\
\hline
\end{tabular}




\section{$3 D$ virtual models $(C A D)$}

The current maturity of computer aided design (CAD) software allows for quick an accurate modelling of three-dimensional workplace layouts in a computer setting. This means that the $3 \mathrm{D}$ representation can be viewed and studied on a computer screen, and (like 2D drawings) can be very easily distributed between participants, even if they are far apart geographically. Another advantage is that it is possible to include human representations (called manikins) inside the $3 \mathrm{D}$ model, and they sometimes include built-in analysis tools such as being able to see out of the eyes of the computer manikin, in order to judge the line of sight. Although it is a matter of education and familiarity with computer environments, it is important to note that some users may feel intimidated by navigating an unfamiliar 3D virtual environment, so it is essential that if virtual 3D models are used, all participants must be familiar and comfortable with navigating the model. If not, the designer runs the risk of getting little or no feedback because the participants may feel reluctant to admit that they could not get a good grasp of what the model tried to convey. In guided group discussions, this can be helped by offering assistance to unfamiliar users, and encouraging than to try out different functionalities offered by the software.

\section{D imaging (digital)}

Recent developments in 3D imaging technology has brought about a large number of new measuring equipment, e.g. structured light sensors, photogrammetry, or 3D laser scanning, that allow us to capture a 3D representation of an existing object or environment (for example, a product or an entire factory). The equipment is either active (meaning that it emits signals and registers the returns) or passive (i.e. simply captures the existing signals). The 3D imaging devices are able to capture, often with very high precision, the spatial position of surfaces found in the environment, and these surfaces are registered as "point clouds", or clusters of positioned points in a digital 3D environment with an orthogonal axis. The equipment often includes an RGB sensor that sweeps the same area and assigns every single data point with colour data, allowing us to see the exact colour and dimension of every object recorded during the 3D scanning. These digital model representations are very useful for getting consensus in a group for the size and shape of a space is that may be the target for a design change, and it is possible to place CAD objects (for example a 3D CAD model of a machine) to see whether it fits in the existing architecture. These models may be a category apart, as they serve more as a visual discussion aid for stakeholder input, but the participatory aspect of being able to change the model interactively is currently limited.

\section{Study questions}

\section{Warm-up:}

Q6.1) What is the difference between intrinsic and extrinsic motivation?

Q6.2) What is the benefit of positive stress, and the drawback of negative stress?

Q6.3) Explain why chronic stress is a workplace risk. 
Q6.4) Why is it OK to carry out "boring" routine tasks when one is a beginner?

Q6.5) What are the benefits of participatory design?

\section{Look around you:}

Q6.6) Consider any profession within an organization that you are familiar with - what organizational mechanisms and routines are in place to provide specific workers with an appropriate level of control, demand and support in their tasks?

\section{Connect this knowledge to an improvement project}

- See question 6.6: if you are observing work in an organization, try to list the organizational mechanisms and routines in place to provide workers with an appropriate level of control, demand and support. If you see that any of these components are under- or over-dimensioned in such a way that work or teamwork is negatively impacted, list it as an improvement potential.

- Use the ideas of demand, control and support to guide face-to-face interviews with workers. Also consider asking about sources of stress, boredom, motivation and demotivation. The NASA-TLX may offer inspiration.

- Use models (in 2D or 3D) representing the workplace to discuss improvement potentials with workplace stakeholders. Use the model representation to steer the discussion of how the workplace design supports or hinders tasks. Also, use a human representation to let discussion participants show movement pathways, positioning and space requirements.

\section{Connection to other topics in this book:}

- The task analysis described in Chapter 7 is a good first step towards addressing psychosocial factors in a structured manner. Hierarchical breakdowns can make it easier to map identified psychosocial risks associated with a particular operation (such as a particularly stressful one).

- Environmental factors (Chapter 12) may be stressors in and of themselves, sometimes without workers realizing it. Sometimes a demanding environment may be a critical factor in exhaustion and burnout, particularly if combined with problematic job demands or dysfunctional teamwork and leadership.

- Aspects of socially sustainable workplaces (Chapter 13) are tightly coupled to psychosocial factors and participation. The likelihood that valuable employees want to remain with the company in the long run is usually tightly coupled to the job's psychosocial factors, particularly participation and motivation. 


\section{Summary}

- A way to look at the concept of leadership in the context of designing workplaces is to define it as "creating the right conditions for other people to perform".

- A psychosocially healthy workplace strives towards low negative stress, high motivation, and the right levels of control, demands, decision latitude, support and supervision.

- Stress can be positive or negative - when positive it challenges, motivates and increases alertness; when negative it can cause physical health problems, strain, anxiety and chemical imbalance.

- The demand-control-support models by Karasek and Theorell illustrate how these psychosocial factors influence performance, engagement and well-being. They also offer an explanation for the occurrence of positive and negative stress.

- Determining appropriate levels of support and supervision are the responsibility of the leadership, and the type of leadership that is appropriate varies depending on the competence level and maturity of the individual employee.

- The right levels of control, demands, decision latitude, support and supervision encourage employees to grow both in confidence and competence.

- Some "conditions for people to perform" are very much influenced by good or bad workplace and/or equipment design, but can also be influenced by the workers' ability to accept, reject or influence those designs.

- A good technique for fostering more worker engagement and sharing of knowledge is to use participatory techniques using models of the design proposals to stimulate discussions and questioning.

\section{Notes}

${ }^{1}$ Sometimes, people who actively seek out stressful or exciting situations (known as "adrenaline junkies") specifically to experience the adrenaline release experience a self-induced high. However, it would be too much of a simplification to say that this is purely because of adrenaline, since other substances like endorphins (positive neurotransmitters) may also be released.

${ }^{2}$ In some circles, participative design maybe a more accepted term if the purpose is to collect more input than just ergonomics aspects, so choose what to call it based on the interests of your target audience.

\subsection{References}

Hart, S., \& Staveland, L. (1988). Development of NASA-TLX (Task Load Index): Results of empirical and theoretical research. In P. Hancock \& N. Meshkati (Eds.), Human Mental Workload (pp. 139-183). Amsterdam: North Holland. 
Hitchcock, D., Willard, M. (2013). Confused about social sustainability? What it means for organizations in developed countries. [Online] Available from: http://www.sustainabilityprofessionals.org/ sites/default/files/Confused\%20about\%20social\%20sustainability_0.pdf [Accessed 24 Feb 2015].

Gasper, K., Middlewood, B.L. (2014). Approaching novel thoughts: Understanding why elation and boredom promote associative thought more than distress and relaxation. Journal of Experimental Social Psychology, 52, 50-57. ISSN 0022-1031. http://dx.doi.org/10.1016/j.jesp.2013.12.007.

Karasek, R. (1979) Job Demands, Job Decision Latitude, and Mental Strain: Implications for Job Redesign. Administrative Science Quarterly, 24 (2), 285-308.

Karasek, R. \& Theorell, T. (1990). Healthy Work: Stress, Productivity, and the Reconstruction of Working Life. New York: Basic Books.

Kuijt-Evers, L. (2006). Comfort in using hand tools: Theory, design and evaluation. S.l: TNO Kwaliteit van Leven, Arbeid.

Maslow, A. H. (1943) A theory of human motivation. Psychological Review, 50 (4): 370-396.

Max-Neef, M. (1992). Development and human needs. In: Ekins, P., Max-Neef, M. (Eds.), Real Life Economics. London: Routledge. 197-214.

NASA. (2014). NASA Task Load Index [Online]. Available from: http://humansystems.arc.nasa.gov/ groups/TLX/downloads/TLXScale.pdf. [Accessed 9 Jan 2014].

Vink, P., Nichols, S. \& Davies, R. C. (2005). Participatory ergonomics and comfort. In: Comfort in Design: Principles and Good Practice. Vink, P. (Ed.). Boca Raton: CRC Press. 41-54.

Wilson, J. R. (1995). Solution ownership in participative work redesign: The case of a crane control room. International Journal of Industrial Ergonomics, 15 (5): 329-344. 